\title{
Evaluation of gene-environment interactions for colorectal cancer susceptibility loci using case-only and case- control designs
}

Nan Song ${ }^{1,2}$, Jeeyoo Lee ${ }^{3}$, Sooyoung $\mathrm{Cho}^{3}$, Jeongseon Kim ${ }^{4}$, Jae Hwan $\mathrm{Oh}^{5}$ and Aesun Shin ${ }^{1,3^{*}}$ (D)

\begin{abstract}
Background: Genome-wide association studies (GWAS) have identified more than 40 colorectal cancer susceptibility loci, but only a small fraction of heritability was explained. To account for missing heritability, we investigated gene-environment interactions ( $\mathrm{G} \times \mathrm{Es}$ ) between GWAS-identified single-nucleotide polymorphisms (SNPs) and established risk or protective factors for colorectal cancer using both case-only and case-control study designs.
\end{abstract}

Methods: Data on 703 colorectal cancer cases and 1406 healthy controls from the National Cancer Center in Korea were used. We tested interactions between 31 GWAS-identified SNPs and 13 established risk or protective factors for colorectal cancer (family history, body mass index, history of colorectal polyps, inflammatory bowel disease, and diabetes mellitus, alcohol drinking, smoking, regular exercise, regular aspirin use, postmenopausal hormone replace therapy, red meat and processed meat intake, and dairy consumption). Logistic regression models were used to assess $\mathrm{G} \times$ Es for colorectal cancer risk.

Results: The SNP rs4444235 at 14q22.2 interacted with regular exercise in colorectal cancer $\left(p_{\text {case-only }}=2.4 \times 10^{-3}\right.$, $\left.p_{\text {case-control }}=1.5 \times 10^{-3}\right)$. The risk allele (C) of rs4444235 increased the risk of colorectal cancer in regularly exercising individuals $(\mathrm{OR}=1.47,95 \% \mathrm{Cl}=1.02-2.10)$ but decreased the risk in non-exercising individuals $(\mathrm{OR}=0.76,95 \% \mathrm{Cl}=$ 0.62-0.94). Furthermore, the $\mathrm{G} \times \mathrm{E}$ between the SNP rs2423279 at 20p12.3 and regular aspirin use was statistically significant $\left(p_{\text {case-only }}=7.7 \times 10^{-3}, p_{\text {case-control }}=1.6 \times 10^{-3}\right)$. The additive effect of the risk allele (T) of rs2423279 on colorectal cancer risk was increased among regular aspirin users $(\mathrm{OR}=4.62,95 \% \mathrm{Cl}=1.97-10.80)$.

Conclusion: Our results suggest that SNP rs4444235 at 14q22.2 and SNP rs2423279 at 20p12.3 may interact with regular exercise and aspirin use in colorectal carcinogenesis.

Keywords: Colorectal cancer, Gene-environment interaction, Single-nucleotide polymorphism, Case-only design, Case-control design

\footnotetext{
* Correspondence: shinaesun@snu.ac.kr

${ }^{1}$ Cancer Research Institute, Seoul National University, Seoul, South Korea

${ }^{3}$ Department of Preventive Medicine, College of Medicine, Seoul National

University, Seoul, South Korea

Full list of author information is available at the end of the article
}

(c) The Author(s). 2019 Open Access This article is distributed under the terms of the Creative Commons Attribution 4.0 International License (http://creativecommons.org/licenses/by/4.0/), which permits unrestricted use, distribution, and reproduction in any medium, provided you give appropriate credit to the original author(s) and the source, provide a link to the Creative Commons license, and indicate if changes were made. The Creative Commons Public Domain Dedication waiver (http://creativecommons.org/publicdomain/zero/1.0/) applies to the data made available in this article, unless otherwise stated. 


\section{Background}

The genetic heritability for colorectal cancer was approximately $35 \%$ (95\% confidence interval $(\mathrm{CI})=10$ $48 \%$ ) in a twin study [1]. Furthermore, common singlenucleotide polymorphisms (SNPs) were expected to explain at least $7.4 \%$ of the heritability [2]. Although genome-wide association studies (GWASs) have identified more than 40 genetic susceptibility regions related to colorectal cancer risk with a nominal genome-wide significance threshold $\left(p\right.$-value $\left.=5 \times 10^{-8}\right)$ [3], the common SNPs discovered by previous GWAS only accounted for $0.65 \%$ of the heritability of colorectal cancer, resulting in remaining missing heritability [2]. Accordingly, gene-environment interactions $(\mathrm{G} \times \mathrm{Es})$ were suggested to contribute to the missing heritability [4]. Furthermore, since GWAS-identified SNPs might be located on non-coding regions or unknown genes of the DNA since due to a non-hypothesis-driven approach of GWAS, elucidation $\mathrm{G} \times$ Es may allow a a better understanding of the biological mechanism of the genetic variations [5].

To investigate the potential contribution of $\mathrm{G} \times \mathrm{Es}$ to colorectal cancer, several studies have evaluated $\mathrm{G} \times \mathrm{Es}$ for colorectal cancer susceptibility loci identified by previous GWAS [6-13] and at a genome-wide level [14]. Most studies have adopted a case-control study design to study $\mathrm{G} \times$ Es [6-12], which has the advantage of being relatively robust and maintaining a desired type I error rate [15]. Few studies on $\mathrm{G} \times \mathrm{Es}$ have used a case-only design for colorectal cancer [13, 14]. Although the caseonly design on $\mathrm{G} \times \mathrm{Es}$ is considered an alternative to case-control design due to potential false positives by unverified assumption of independence between genetic and environmental factors, it allows for more efficient estimation and more powerful association tests to be performed on $\mathrm{G} \times$ Es than case-control design [16].

For robust and powerful detection, we used both caseonly and case-control approaches to investigate $\mathrm{G} \times \mathrm{Es}$ for colorectal cancer. We focused on 31 SNPs in colorectal cancer susceptibility loci identified by previous GWAS and 13 established environmental risk or protective factors.

\section{Methods}

\section{Study population}

The study population was recruited from the National Cancer Center (NCC) in Korea as previously reported [11-13] and presented in Additional file 1: Figure S1. In brief, among 1427 incident colorectal cancer cases who were diagnosed and had a surgery between 2010 and 2013, 1070 cases agreed to participate in the study. We excluded patients who did not complete questionnaires or patients whose blood samples were not insufficient for genotyping. Thus, a total of 703 colorectal cancer patients were included in the analyses. The 14201 healthy controls were recruited among people who underwent a health screening examination, which was a benefit program of the National Health Insurance between 2007 and 2014. Among 9037 people who consented to participate in the study and completed the questionnaire, a total of 1406 healthy controls were included in the analyses by 1:2 frequency matching on 5year age and sex. All study participants provided written informed consent, and the study was approved by the institutional review board (IRB) of the NCC (IRB No. NCCNCS-10-350 and NCC 2015-0202).

\section{Data collection}

In this study, the established colorectal cancer risk or protective factors were defined as factors or interventions with adequate evidence of increased or decreased risk of colorectal cancer based on the latest Physician Data Query (PDQ ${ }^{\circ}$ ) cancer information summaries on colorectal cancer prevention of the National Cancer Institute (NCI) updated by Mar 1, 2018 [17] and the Colorectal Cancer Facts \& Figs. 2017-2019 of American Cancer Society $\left(\mathrm{ACS}^{\circ}\right)$ [18]. Accordingly, the environmental factors considered in this analysis included family history of colorectal cancer, BMI, history of colorectal polyps, history of inflammatory bowel disease (IBD), history of DM, postmenopausal HRT, red meat intake, processed meat intake, and dairy consumption. Milk consumption was excluded in this analysis due to substantial overlap with diary product consumption.

The data for the selected environmental factors were collected from the structured questionnaires composed of two parts: one was concerned with demographic and epidemiological factors, described in detail elsewhere [11], and the other was a semiquantitative food frequency questionnaire (SQFFQ) [19]. Face-to-face interviews were conducted for colorectal cancer patients by trained interviewers using the written questionnaires. Controls completed the questionnaires themselves and their responses were validated by telephone interviews. The questionnaires were developed based on Korean National Health and Nutrition Examination survey, where internal quality assurance as well as external quality control program were managed by the Korea Centers for Disease Control and Prevention [20].

\section{SNP selection and genotyping}

We included 31 SNPs previously identified to be associated with colorectal cancer risk with nominal genomewide statistical significance ( $p$-value $\left.<5 \times 10^{-8}\right)$ as described previously in detail [11-13]. DNA extraction and genotyping were performed on BioRobot M48 automatic extraction equipment with the MagAttract DNA Blood M48 Kit (Qiagen, Hilden, Germany) and an Agenabio 
MassArray iPLEX ${ }^{\circ}$ gold assay (Agena Bioscience, Inc., San Diego, CA, US). Briefly, the genotype data for any SNPs were excluded according to the quality control procedures for the following reasons: genotyping failure, monomorphic or minor allele frequency $(\mathrm{MAF})<0.01$, or $p$-value for deviations from Hardy-Weinberg equilibrium $(\mathrm{HWE})<0.01$ in controls.

\section{Statistical analysis}

To test the difference in the distribution of environmental factors between colorectal cancer cases and controls, a chi-square test for categorical variables and a T-test for continuous variables were conducted. The environmental factors were dichotomized, and a category known to be a lower risk group for colorectal cancer was considered as a reference. For genetic factors, individual SNP alleles were designated as risk or effect alleles based on the literature review. Based on each genotype of SNPs coded as 0,1 , or 2 copies of risk or effect alleles, we calculated MAF, risk or effect allele frequency (RAF), and $p$-value for deviations from HWE in controls. To assess the effects of the environmental factors and genetic factors assuming a log-additive model on colorectal cancer risk, a logistic regression model was used.

To detect the statistical significance of $\mathrm{G} \times \mathrm{Es}$, we employed both case-only and case-control designs. In the case-only analysis, each SNP genotype was treated as an independent variable, and each status of dichotomized environmental factors was treated as a dependent variable using a logistic regression model. Under the same setting, control-only analysis was also conducted to test the assumption of independence between genetic and environmental factors. In case-control logistic analysis on colorectal cancer risk, independent variables included not only the SNP genotype and binary status of environmental factors but also the meaning of $\mathrm{G} \times \mathrm{E}$ terms of those genetic and environmental factors. To be eligible for further analysis, the SNPs for which the nominal $p$-value for $\mathrm{G} \times \mathrm{E}$ was $<0.05$ in both case-only and case-control analyses and at least one $p$-value for $\mathrm{G} \times \mathrm{E}$ was $<1.61 \times 10^{-3}$ (Bonferroni-corrected $p$-value; $0.05 / 31$ ) to account for multiple testing were selected. To evaluate the genetic effects on colorectal cancer risk that were modified by environmental factors, association tests for the selected SNPs with statistically significant $p$ values for $\mathrm{G} \times \mathrm{E}$ were conducted, stratified by corresponding environmental factor status. For those SNPs, we estimated effects for each genotype as well as effects assuming log-additive, dominant, and recessive models.

The logistic models that only included genetic variables were unadjusted. If models included environmental variables, all analyses were adjusted for age and sex. Potential confounders were chosen based on an association test between environmental factors and colorectal cancer risk. To prevent a problem of multicollinearity among the potential confounders, if a statistically significant correlation was observed between any two paired variables, the variable making a smaller contribution to colorectal cancer risk was dropped. Accordingly, analyses were adjusted for age, sex, family history of colorectal cancer, history of DM, regular exercise, and dairy consumption. Moreover, the dietary factor values were adjusted for total energy intake using the residual method as described elsewhere [21]. All associations and statistical significance were estimated by odds ratio (OR), 95\% $\mathrm{CI}$, and two-sided $p$-value using SAS 9.4 software (SAS Institute, Inc., Cary, NC, US).

\section{Results}

Table 1 shows the characteristics of the study population and their associations with colorectal cancer risk. Our study population consisted of 703 colorectal cancer cases and 1406 healthy controls. Given that cases and controls were frequency-matched by age and sex, they had a similar mean age (56.4 years in cases and 56.0 years in controls) and the same distribution of sex (31.7\% women and $68.3 \%$ men). We observed statistically significant differences in family history of colorectal cancer, BMI, history of DM, regular exercise, regular aspirin use, postmenopausal HRT use, red and processed meat intake, and dairy product consumption $(P<0.05)$. After adjustment for covariates, we observed a statistically significant association for an increased risk of colorectal cancer with family history of colorectal cancer $(\mathrm{OR}=$ 2.27, 95\% CI $=1.56-3.32, P<0.01)$, history of DM $(\mathrm{OR}=$ 2.27, $95 \% \mathrm{CI}=1.56-3.32, P<0.01)$, nonregular exercise $(\mathrm{OR}=2.97,95 \% \mathrm{CI}=2.43-3.62, P<0.01)$, nonregular aspirin use $(\mathrm{OR}=3.26,95 \% \mathrm{CI}=1.97-5.41, P<0.01)$, and dairy consumption less than $400 \mathrm{~g} /$ day $(\mathrm{OR}=2.23,95 \%$ $\mathrm{CI}=1.53-3.25, \quad P<0.01)$. Contrary to previous studies, we observed a statistically significant association for a decreased risk of colorectal cancer with red meat intake equal to or greater than $100 \mathrm{~g} /$ day $(\mathrm{OR}=0.66,95 \% \mathrm{CI}=$ $0.47-0.92, P=0.02$ ).

Table 2 shows the associations between susceptibility SNPs and colorectal cancer risk in previously published GWAS and the current study. Among 31 previously reported SNPs, 13 SNPs (rs647161 at 5q31.1, rs6983267 at $8 \mathrm{q} 24.21$, rs7014346 at $8 \mathrm{q} 24.21$, rs 10505477 at $8 \mathrm{q} 24.21$, rs10795668 at 10p14, rs704017 at 10q22.3, rs11196172 at $10 \mathrm{q} 25.2, \mathrm{rs} 174537$ at $11 \mathrm{q} 12.2, \mathrm{rs} 174550$ at $11 \mathrm{q} 12.2$, rs1535 at $11 \mathrm{q} 12.2, \mathrm{rs} 4779584$ at $15 \mathrm{q} 13.3$, rs 10411210 at $19 q 13.11$, and rs2423279 at 20p12.3) showed statistical evidence of association with colorectal cancer risk in the same direction as previous results, with nominal $p$ values ranging from 0.05 to $2.0 \times 10^{-4}$. The remaining 10 SNPs (rs3802842 at 11q23.1, rs10849432 at 12p13.31, rs10774214 at $12 \mathrm{p} 13.32$, rs7136702 at $12 \mathrm{q} 13.13$, 
Table 1 Characteristics of colorectal cancer cases and controls and associations with colorectal cancer risk

\begin{tabular}{|c|c|c|c|c|c|c|c|c|}
\hline \multirow[t]{3}{*}{ Characteristics } & \multicolumn{2}{|c|}{ Colorectal cancer cases } & \multicolumn{2}{|c|}{ Controls } & \multirow[t]{3}{*}{$p^{a}$} & \multirow[t]{3}{*}{ OR } & \multirow[t]{3}{*}{$(95 \% \mathrm{Cl})^{\mathrm{b}}$} & \multirow[t]{3}{*}{$p^{b}$} \\
\hline & \multicolumn{2}{|c|}{$(N=703,100 \%)$} & \multicolumn{2}{|c|}{$(N=1406,100 \%)$} & & & & \\
\hline & $\bar{N}$ & (\%) & $\bar{N}$ & (\%) & & & & \\
\hline \multicolumn{9}{|l|}{ Age, years } \\
\hline mean (SD) & 56.4 & (9.6) & 56.0 & (9.1) & 0.31 & & & \\
\hline$<50$ & 159 & (22.6) & 318 & $(22.6)$ & $>0.99$ & 1.00 & (ref.) & \\
\hline$\geq 50$ & 544 & $(77.4)$ & 1088 & $(77.4)$ & & 1.10 & $(0.87-1.40)$ & 0.41 \\
\hline \multicolumn{9}{|l|}{ Sex } \\
\hline Women & 223 & $(31.7)$ & 446 & $(31.7)$ & $>0.99$ & 1.00 & (ref.) & \\
\hline Men & 480 & $(68.3)$ & 960 & $(68.3)$ & & 0.96 & $(0.78-1.18)$ & 0.68 \\
\hline \multicolumn{9}{|c|}{ Family history of colorectal cancer } \\
\hline No & 636 & $(90.5)$ & 1339 & $(95.2)$ & $<0.01$ & 1.00 & (ref.) & \\
\hline Yes & 67 & $(9.5)$ & 67 & (4.8) & & 2.27 & $(1.56-3.32)$ & $<0.01$ \\
\hline \multicolumn{9}{|l|}{$\mathrm{BMI}, \mathrm{kg} / \mathrm{m}^{2}$} \\
\hline mean (SD) & 23.8 & (3.4) & 24.1 & $(2.7)$ & 0.04 & & & \\
\hline$<25.0$ & 478 & $(68.0)$ & 930 & $(66.2)$ & 0.47 & 1.00 & (ref.) & \\
\hline$\geq 25.0$ & 225 & (32.0) & 470 & (33.4) & & 0.87 & $(0.71-1.07)$ & 0.19 \\
\hline \multicolumn{9}{|c|}{ History of colorectal polyps } \\
\hline No & 628 & $(89.3)$ & 1227 & $(87.3)$ & 0.17 & 1.00 & (ref.) & \\
\hline Yes & 75 & $(10.7)$ & 179 & $(12.7)$ & & 0.94 & $(0.69-1.28)$ & 0.70 \\
\hline \multicolumn{9}{|l|}{ History of IBD } \\
\hline No & 701 & $(99.7)$ & 1401 & (99.6) & 0.79 & 1.00 & (ref.) & \\
\hline Yes & 2 & $(0.3)$ & 5 & $(0.4)$ & & 0.67 & $(0.12-3.87)$ & 0.66 \\
\hline \multicolumn{9}{|l|}{ History of DM } \\
\hline No & 616 & (87.6) & 1287 & $(91.5)$ & $<0.01$ & 1.00 & (ref.) & \\
\hline Yes & 87 & $(12.4)$ & 119 & (8.5) & & 2.27 & $(1.56-3.32)$ & $<0.01$ \\
\hline \multicolumn{9}{|c|}{ Alcohol drinking } \\
\hline Never & 212 & $(30.2)$ & 419 & $(29.8)$ & 0.87 & 1.00 & (ref.) & \\
\hline Ever & 491 & $(69.8)$ & 987 & $(70.2)$ & & 1.07 & $(0.84-1.36)$ & 0.59 \\
\hline \multicolumn{9}{|l|}{ Smoking } \\
\hline Never & 316 & $(45.0)$ & 617 & $(43.9)$ & 0.64 & 1.00 & (ref.) & \\
\hline Ever & 387 & $(55.1)$ & 789 & $(56.1)$ & & 0.88 & $(0.68-1.15)$ & 0.36 \\
\hline \multicolumn{9}{|c|}{ Regular exercise } \\
\hline Yes & 229 & (32.6) & 566 & $(40.3)$ & $<0.01$ & 1.00 & (ref.) & \\
\hline No & 474 & $(67.4)$ & 833 & $(59.3)$ & & 2.97 & $(2.43-3.62)$ & $<0.01$ \\
\hline \multicolumn{9}{|c|}{ Regular aspirin use } \\
\hline Yes & 20 & $(2.8)$ & 134 & $(9.5)$ & $<0.01$ & 1.00 & (ref.) & \\
\hline No & 683 & $(97.2)$ & 1272 & $(90.5)$ & & 3.26 & $(1.97-5.41)$ & $<0.01$ \\
\hline \multicolumn{9}{|c|}{ HRT in postmenopausal women } \\
\hline Ever & 31 & $(19.1)$ & 99 & $(30.9)$ & $<0.01$ & 1.00 & (ref.) & \\
\hline Never & 130 & $(80.3)$ & 219 & $(68.4)$ & & 1.50 & $(0.92-2.44)$ & 0.11 \\
\hline \multicolumn{9}{|c|}{ Red meat intake, g/day ${ }^{c}$} \\
\hline mean (SD) & 51.2 & (33.4) & 58.0 & $(39.0)$ & $<0.01$ & & & \\
\hline$<100$ & 643 & $(87.3)$ & 1228 & $(87.3)$ & $<0.01$ & 1.00 & (ref.) & \\
\hline$\geq 100$ & 58 & (8.3) & 176 & (12.5) & & 0.66 & $(0.47-0.92)$ & 0.02 \\
\hline
\end{tabular}


Table 1 Characteristics of colorectal cancer cases and controls and associations with colorectal cancer risk (Continued)

\begin{tabular}{|c|c|c|c|c|c|c|c|c|}
\hline \multirow[t]{3}{*}{ Characteristics } & \multirow{2}{*}{\multicolumn{2}{|c|}{$\begin{array}{l}\text { Colorectal cancer cases } \\
(N=703,100 \%)\end{array}$}} & \multirow{2}{*}{\multicolumn{2}{|c|}{$\begin{array}{l}\text { Controls } \\
(N=1406,100 \%)\end{array}$}} & \multirow[t]{3}{*}{$P^{a}$} & \multirow[t]{3}{*}{ OR } & \multirow[t]{3}{*}{$(95 \% \mathrm{Cl})^{\mathrm{b}}$} & \multirow[t]{3}{*}{$P^{b}$} \\
\hline & & & & & & & & \\
\hline & $\mathrm{N}$ & $(\%)$ & $\mathrm{N}$ & (\%) & & & & \\
\hline \multicolumn{9}{|c|}{ Processed meat intake, $\mathrm{g} /$ day $^{c}$} \\
\hline mean (SD) & 1.1 & $(9.1)$ & 2.5 & $(13.2)$ & $<0.01$ & & & \\
\hline$<50$ & 699 & $(99.4)$ & 1395 & $(99.2)$ & 0.29 & 1.00 & (ref.) & \\
\hline$\geq 50$ & 2 & $(0.3)$ & 9 & $(0.6)$ & & 0.78 & $(0.16-3.93)$ & 0.77 \\
\hline \multicolumn{9}{|c|}{ Dairy consumption, g/day ${ }^{c}$} \\
\hline mean (SD) & 72.6 & $(147.5)$ & 236.4 & $(807.3)$ & $<0.01$ & & & \\
\hline$\geq 400$ & 16 & $(2.3)$ & 198 & $(14.1)$ & $<0.01$ & 1.00 & (ref.) & \\
\hline$<400$ & 685 & $(97.8)$ & 1206 & $(85.8)$ & & 2.23 & $(1.53-3.25)$ & $<0.01$ \\
\hline
\end{tabular}

rs4444235 at $14 q 22.2$, rs4939827 at $18 q 21.1$, rs1800469 at $19 q 13.2, r s 2241714$ at $19 q 13.2$, rs961253 at 20p12.3, rs4813802 at 20p12.3) of the 18 SNPs showed evidence of association in the same direction even though it was not statistically significant.

The $\mathrm{G} \times$ Es between 31 SNPs and 13 environmental factors were tested using both case-only (Additional file 1: Table S1) and case-control designs (Additional file 1: Table $\mathrm{S} 2$ ). A total of 7 out of $8 \mathrm{G} \times$ Es showing the nominal significance of $p$-value $<0.05$ in both case-only and casecontrol analyses satisfied the assumption of independence between genetic and environmental factors except $1 \mathrm{G} \times \mathrm{E}$ between rs1957636 and smoking status (Additional file 1: Table S3). Table 3 summarizes those $7 \mathrm{G} \times$ Es between rs10849432 and BMI, rs11196172 and history of colorectal polyps, rs10795668 and regular exercise, rs4444235 and regular exercise, rs2241714 and regular aspirin use, rs2423279 and regular aspirin use, and rs1957636 and diary consumption in colorectal cancer by study designs. Notably, $2 \mathrm{G} \times$ Es between rs4444235 and regular exercise (caseonly: $P_{\text {interaction }}=2.4 \times 10^{-3}$, case-control: $P_{\text {interaction }}=1.5 \times$ $10^{-3}$ ) and rs2423279 and regular exercise (case-only: $P_{\text {inter- }}$ action $=7.7 \times 10^{-3}, \quad$ case-control: $\quad P_{\text {interaction }}=1.6 \times 10^{-3}$ ) remained significant in at least one of case-only and casecontrol analyses even after Bonferroni-corrected $p$-value for multiple testing was allowed for.

Table 4 shows the association of 2 SNPs, rs4444235 and rs2423279, with colorectal cancer risk stratified by regular exercise and regular aspirin use. Although the SNP rs4444235 was not significantly associated with colorectal cancer risk (Table 2), the magnitude of the effect of the $\mathrm{C}$ allele for this SNP decreased with regular exercise $\left(\mathrm{OR}_{\mathrm{CC} \text { vs. TT }}=0.58,95 \% \mathrm{CI}=0.38-0.88, \mathrm{OR}_{\text {addi- }}\right.$ tive $=0.76,95 \% \mathrm{CI}=0.62-0.94, \quad \mathrm{OR}_{\text {recessive }}=0.66,95 \%$ $\mathrm{CI}=0.46-0.94$ ) but increased with nonregular exercise
$\left(\mathrm{OR}_{\mathrm{CC} \text { vs. } \mathrm{TT}}=1.47,95 \% \mathrm{CI}=1.02-2.10, \mathrm{OR}_{\text {additive }}=1.21\right.$, $95 \% \mathrm{CI}=1.01-1.44)$. The increased magnitude of the effect of the $\mathrm{T}$ allele for the SNP rs2423279 on colorectal cancer risk was observed in regular aspirin users $\left(\mathrm{OR}_{\mathrm{CT}}\right.$ vs. $\mathrm{CC}=4.77,95 \% \mathrm{CI}=1.28-17.73, \mathrm{OR}_{\mathrm{TT}}$ vs. $\mathrm{CC}=21.19$, 95\% CI $=3.82-117.52, \mathrm{OR}_{\text {additive }}=4.62,95 \% \mathrm{CI}=1.97-$ $10.80, \mathrm{OR}_{\text {dominant }}=6.30,95 \% \mathrm{CI}=1.80-22.09, \mathrm{OR}_{\text {reces- }}$ sive $=8.01,95 \% \mathrm{CI}=2.02-31.78)$.

\section{Discussion}

We evaluated $\mathrm{G} \times \mathrm{Es}$ on colorectal cancer risk for 31 susceptibility SNPs identified through GWAS with 13 established environmental risk or protective factors using both case-only and case-control study designs. Our analysis showed evidence of $\mathrm{G} \times$ Es between the SNP rs4444235 at $14 q 22.2$ and regular exercise and the SNP rs2423279 at 20p12.3 and regular aspirin use after accounting for multiple testing. Furthermore, we observed that the associations between rs4444235 and rs2423279 were modified by regular exercise and regular aspirin use.

Among previous $\mathrm{G} \times \mathrm{E}$ studies for colorectal cancer susceptibility loci identified by GWAS, the $\mathrm{G} \times \mathrm{E}$ between rs4444235 and regular exercise for colorectal cancer risk has not been investigated [6-13]. The $\mathrm{G} \times \mathrm{E}$ between rs2423279 and regular aspirin was tested by Kantor et al., but the interaction was not detected with a statistically significant level [7]. Furthermore, previously reported $\mathrm{G} \times$ Es identified by GWAS for colorectal carcinogenesis were not replicated. This may be due to ethnic differences or limited power to detect interactions. We previously reported on $\mathrm{G} \times \mathrm{Es}$ involving GWASidentified colorectal cancer susceptibility loci with age at cancer onset [13], smoking [11], and alcohol consumption [12] using a conventional method of detecting 


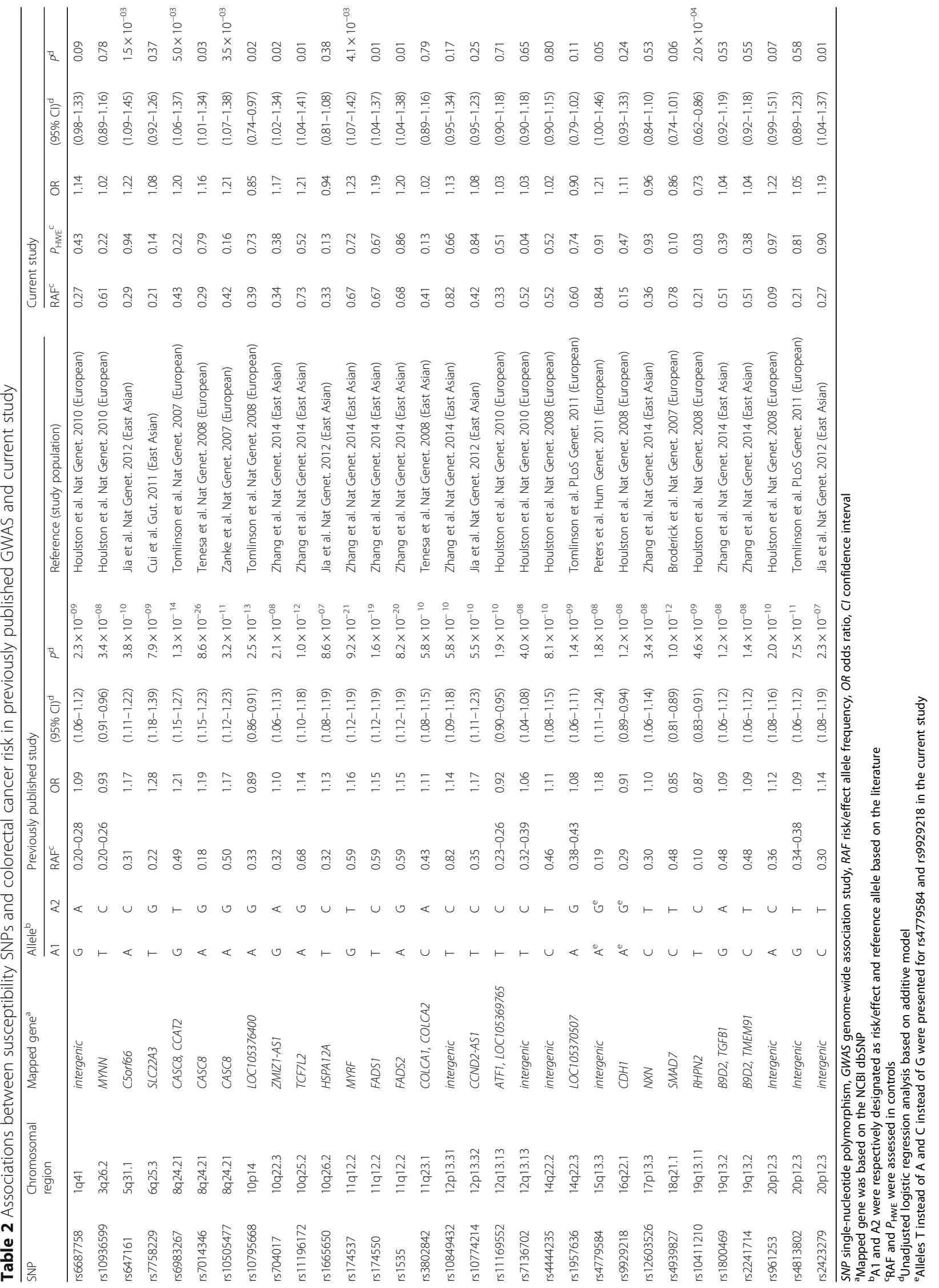




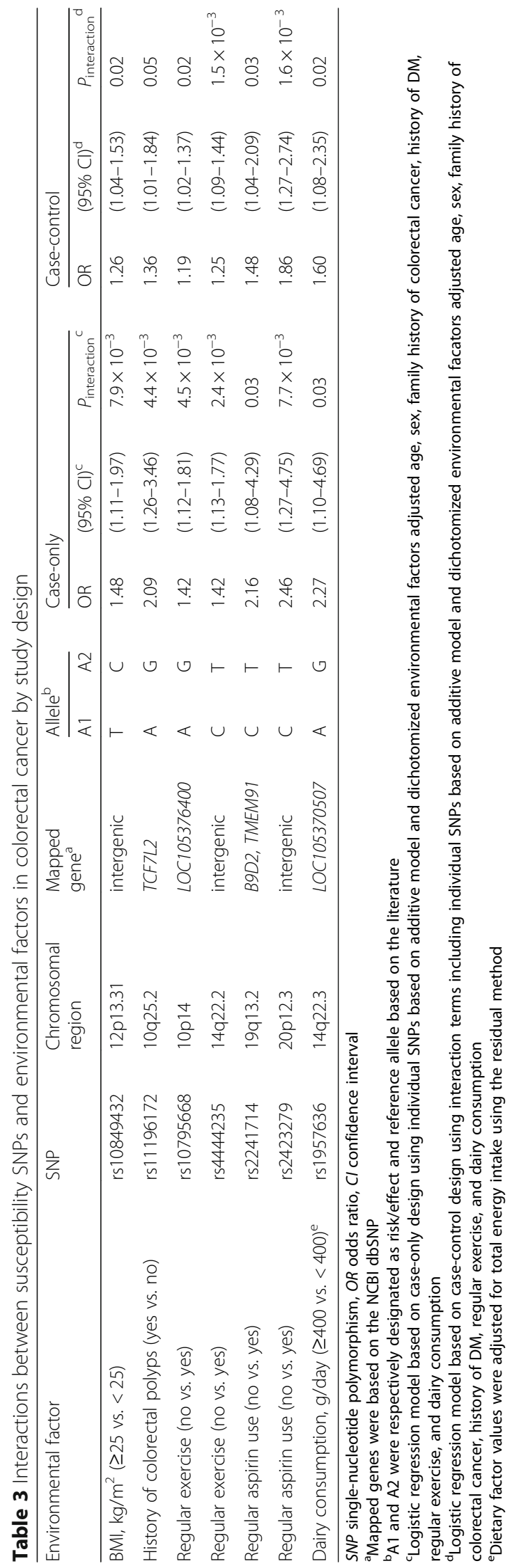


Table 4 Associations between susceptibility SNPs and colorectal cancer risk by environmental factors

\begin{tabular}{|c|c|c|c|c|c|c|c|c|c|c|c|c|}
\hline \multirow[t]{4}{*}{ SNP/genotype ${ }^{a}$} & \multicolumn{12}{|c|}{ Regular exercise } \\
\hline & \multicolumn{6}{|c|}{ Yes } & \multicolumn{6}{|l|}{ No } \\
\hline & \multicolumn{2}{|l|}{ Case } & \multicolumn{2}{|c|}{ Control } & \multirow[t]{2}{*}{ OR } & \multirow[t]{2}{*}{$(95 \% \mathrm{Cl})^{\mathrm{b}}$} & \multicolumn{2}{|l|}{ Case } & \multicolumn{2}{|c|}{ Control } & \multirow[t]{2}{*}{ OR } & \multirow[t]{2}{*}{$(95 \% \mathrm{Cl})^{\mathrm{b}}$} \\
\hline & $\mathrm{N}$ & $(\%)$ & $\mathrm{N}$ & $(\%)$ & & & $\mathrm{N}$ & (\%) & $\mathrm{N}$ & $(\%)$ & & \\
\hline \multicolumn{13}{|c|}{ rs4444235 at 14q22.2 (intergenic) } \\
\hline$\pi$ & 65 & $(28.4)$ & 185 & $(22.2)$ & 1.00 & (ref.) & 98 & (20.7) & 142 & $(25.1)$ & 1.00 & (ref.) \\
\hline $\mathrm{TC}$ & 113 & $(49.3)$ & 411 & $(49.3)$ & 0.82 & $(0.57-1.17)$ & 227 & $(47.9)$ & 272 & $(48.1)$ & 1.28 & $(0.92-1.78)$ \\
\hline CC & 51 & $(22.3)$ & 237 & $(28.5)$ & 0.58 & $(0.38-0.88)$ & 149 & (31.4) & 151 & $(26.7)$ & 1.47 & $(1.02-2.10)$ \\
\hline Additive model & & & & & 0.76 & $(0.62-0.94)$ & & & & & 1.21 & $(1.01-1.44)$ \\
\hline Dominant model & & & & & 0.72 & $(0.52-1.02)$ & & & & & 1.35 & $(0.99-1.83)$ \\
\hline Recessive model & & & & & 0.66 & $(0.46-0.94)$ & & & & & 1.24 & $(0.94-1.64)$ \\
\hline
\end{tabular}

Interaction between rs4444235 and regular exercise

$$
\begin{array}{ll}
\text { Case-only }^{c} & P \text { for interaction }=2.4 \times 10^{-3} \\
\text { Case-control }^{d} & P \text { for interaction }=1.5 \times 10^{-3}
\end{array}
$$

\begin{tabular}{|c|c|c|c|c|c|c|c|c|c|c|c|c|}
\hline CC & 5 & $(25.0)$ & 75 & $(56.0)$ & 1.00 & (ref.) & 337 & (49.8) & 679 & (53.5) & 1.00 & (ref.) \\
\hline $\mathrm{CT}$ & 10 & $(50.0)$ & 53 & (39.6) & 4.77 & $(1.28-17.73)$ & 278 & (41.1) & 498 & $(39.2)$ & 1.07 & $(0.87-1.33)$ \\
\hline$\pi$ & 5 & $(25.0)$ & 6 & $(4.5)$ & 21.19 & $(3.82-117.52)$ & 62 & $(9.2)$ & 93 & (7.3) & 1.27 & $(0.87-1.85)$ \\
\hline Additive model & & & & & 4.62 & $(1.97-10.80)$ & & & & & 1.10 & $(0.94-1.29)$ \\
\hline Dominant model & & & & & 6.30 & $(1.80-22.09)$ & & & & & 1.11 & $(0.90-1.35)$ \\
\hline Recessive model & & & & & 8.01 & $(2.02-31.78)$ & & & & & 1.23 & $(0.86-1.77)$ \\
\hline
\end{tabular}

rs2423279 at 20p12.3 (intergenic)

Interaction between rs2423279 and regular aspirin use

$$
\begin{array}{ll}
\text { Case-only }^{c} & P \text { for interaction }=7.7 \times 10^{-3} \\
\text { Case-control }^{d} & P \text { for interaction }=1.6 \times 10^{-3}
\end{array}
$$

SNP single-nucleotide polymorphism, $\mathrm{OR}$ odds ratio, $\mathrm{Cl}$ confidence interval, $\mathrm{DM}$ diabetes mellitus

${ }^{a}$ Risk/effect and reference allele was designated based on the literature

${ }^{b}$ Logistic regression modeladjusted age, sex, family history of colorectal cancer, history of DM, regular exercise, and dairy consumption

'Logistic regression model based on case-only design using individual SNPs based on additive model and dichotomized environmental facators adjusted age, sex, family history of colorectal cancer, history of DM, regular exercise, and dairy consumption

${ }^{\mathrm{d} L o g i s t i c}$ regression model based on case-control design using interaction terms including individual SNPs based on additive model and dichotomized

environmental facators adjusted age, sex, family history of colorectal cancer, history of DM, regular exercise, and dairy consumption

interactions. In the current analysis, we combined the case-only, case-control, and control-only study designs, suggesting that the results were more powerful and less biased.

Colorectal cancer susceptibility associated with the SNP rs4444235 was first reported by meta-analysis of two GWAS from individuals of European descent [22]. The association between rs4444235 and colorectal cancer risk was also detected among Caucasian and east Asian patients by a meta-analysis [23]. Although several Asian studies [24-26] as well as the current study did not show a statistical association between rs4444235 and colorectal cancer risk, perhaps due to a small sample size, the direction of the association was consistent, suggesting a potential higher risk associated with the $\mathrm{C}$ allele. rs4444235 is located at chromosome 14q22.2 close to the bone morphogenetic protein 4 (BMP4) coding gene. Despite the noncoding risk variant, the $\mathrm{C}$ allele of rs4444235 showed significantly increased allele-specific expression of the BMP4 gene in the colorectal cancer cell line [27]. BMP4 is involved in the transforming growth factor beta (TGF $\beta$ ) superfamily signaling pathway, contributing to colorectal tumorigenesis [28]. Colorectal tumorigenesis may be inhibited by favorable effects of regular exercise stimulating intestinal peristalsis and maintaining the general metabolic milieu [29].

This association between the SNP rs2423279 and colorectal cancer risk was identified by GWAS in east Asians and replicated in east Asians and European-ancestry populations as well [30]. This study also observed that rs2423279 with the $\mathrm{C}$ allele was associated with an increased risk of colorectal cancer in the same direction. The 2,423,279 is located at chromosome 20p12.3 close to $H A O 1$, which encodes hydroxy acid oxidase 1 , and $P L C B 1$, which encodes phospholipase $C$ beta 1 . In terms of $H A O 1$ or PLBC1 genes, the mechanisms of colorectal carcinogenesis and interaction with aspirin are unknown. However, because aspirin can be used as a ligand 
and/or transport and absorption facilitators of diverse agents, including RNAi or polynucleotide targeting for inhibition of HAO1 gene expression [31, 32], there still remains a possibility of indirect $\mathrm{G} \times$ Es between $H A O 1$ and aspirin use.

A major strength of this study is that we found novel $\mathrm{G} \times \mathrm{Es}$ for colorectal cancer susceptibility loci between SNP rs4444235 and regular exercise and SNP rs2423279 and regular aspirin use after accounting for multiple testing. However, the calculated power was $32.2 \%$ for the $\mathrm{G} \times \mathrm{E}$ between $\mathrm{rs} 4444235$ and regular exercise and $53.2 \%$ for the $\mathrm{G} \times \mathrm{E}$ between $\mathrm{rs} 2423279$ and regular aspirin use considering the case-only analysis with 703 cases. Although we did not obtain enough statistical power to detect weak $G \times$ Es due to insufficient sample size, both case-only and case-control analyses were performed to overcome sample size limitations, derive additional power, and ensure general validity. Through additional control-only analysis, the assumption of independence of genetic and environmental factors was tested in the underlying population. Also, because the case-only study design estimated interactions on the multiplicative scale, which could not imply that $\mathrm{G} \times$ Es biologically cause colorectal cancer, case-control study design validated the biological hypotheses.

One limitation is that we did not include all colorectal susceptibility loci identified by previous GWAS in the analyses. However, our genetic factors included a relatively updated and large number of colorectal cancer susceptibility SNPs compared with previous $\mathrm{G} \times \mathrm{E}$ studies for colorectal cancer. Environmental factors in the analysis were also selected based on the latest evidence for colorectal cancer risk or protective factors. The other limitation is that the biological basis of $G \times E s$ for GWAS-identified SNPs remains unclear, because the functional relationship between those SNPs based on the agnostic approach and colorectal cancer risk are not fully understood. Third, the observed $\mathrm{G} \times$ Es have not been validated in the other population. We further conducted case-only and case-control analysis on $\mathrm{G} \times$ Es between rs4444235 and regular exercise among Whites in UK Biobank, no statistically significant interactions were observed (Additional file 1: Table S4). Further studies for Asian-based established risk and protective factors on colorectal cancer and validation studies with sufficient sample size are warranted.

\section{Conclusions}

In conclusion, our results suggest that there are possible interactions between the SNP rs4444235 at $14 \mathrm{q} 22.2$ and regular exercise and the SNP rs2423279 at $20 \mathrm{p} 12.3$ and regular aspirin use in colorectal carcinogenesis.

\section{Additional files}

Additional file 1 : Figure S1. A flow diagram of the study population. Table S1. Interactions between susceptibility SNPs and environmental factors in colorectal cancer by case-only analysis. Table S2. Interactions between susceptibility SNPs and environmental factors in colorectal cancer by case-control analysis. Table S3. Independence test between selected susceptibility SNPS and environmental factors by control-only analysis. Table S4. Associations between rs4444235 and colorectal cancer risk by regular exercise among Whites in UK Biobank.

\begin{abstract}
Abbreviations
ACS: American Cancer Society; BMP4: Bone morphogenetic protein 4; $\mathrm{Cl}$ : Confidence interval; G×E: Gene-environment interaction;

GWAS: Genome-wide association study; HWE: Hardy-Weinberg equilibrium; IBD: Inflammatory bowel disease; IRB: Institutional review board; MAF: Minor allele frequency; NCC: National Cancer Center; NCl: National Cancer Institute; NRF: National Research Foundation of Korea; OR: Odds ratio; PDQ: Physician Data Query; RAF: Risk allele frequency; SNP: Single-nucleotide polymorphism; SQFFQ: Semiquantitative food frequency questionnaire; TGF $\beta$ : Transforming growth factor beta
\end{abstract}

\section{Acknowledgements}

Not applicable.

\section{Authors' contributions}

NS made contributions to study conceptualization and design, data analysis, interpretation the results, funding acquisition and was a major contributor in writing the manuscript. JL made contributions to data analysis and involved in revising the manuscript. SC was involved in data analysis and revising the manuscript. JK contributed to data collection and funding acquisition and was involved in revising the manuscript critically for intellectual content. JHO made substantial contribution to acquisition of data and involved in revising the manuscript critically for intellectual content and funding acquisition. AS made contributions to study conceptualization and design, data interpretation, revising the manuscript critically for intellectual content, and funding acquisition. All authors critically reviewed this manuscript and approved the final version to be published.

\section{Funding}

This work was supported by the Basic Science Research Program through the National Research Foundation of Korea (NRF) funded by the Ministry of Education (2009-0093820, 2010-0010276, 2016R1D1A1B04935872, 2017R1A2B4009233) and by National Cancer Center (NCC) in Korea (0910220, 1210141). The funding bodies have no role in study design, collection, analysis, interpretation of data or writing the manuscript.

\section{Availability of data and materials}

The datasets generated during and/or analyzed during the current study are available from the corresponding author on reasonable request.

\section{Ethics approval and consent to participate}

All study participants provided written informed consent, and the study was approved by the institutional review board (IRB) of the NCC (IRB No. NCCNCS-10-350 and NCC 2015-0202).

\section{Consent for publication}

Not applicable.

\section{Competing interests}

Aesun Shin is an editorial board member (Associate Editor) of BMC Cancer. The other authors declare that they have no competing interests.

\section{Author details}

${ }^{1}$ Cancer Research Institute, Seoul National University, Seoul, South Korea. 2Department of Epidemiology and Cancer Control, St. Jude Children's Research Hospital, Memphis, TN, USA. ${ }^{3}$ Department of Preventive Medicine, College of Medicine, Seoul National University, Seoul, South Korea.

${ }^{4}$ Molecular Epidemiology Branch, National Cancer Center, Goyang, South 
Korea. ${ }^{5}$ Center for Colorectal Cancer, National Cancer Center, Goyang, South Korea.

\section{Received: 31 October 2019 Accepted: 11 December 2019}

\section{- 10 010}

\section{References}

1. Lichtenstein P, Holm NV, Verkasalo PK, lliadou A, Kaprio J, Koskenvuo M, Pukkala E, Skytthe A, Hemminki K. Environmental and heritable factors in the causation of cancer--analyses of cohorts of twins from Sweden, Denmark, and Finland. N Engl J Med. 2000;343(2):78-85.

2. Jiao S, Peters U, Berndt S, Brenner H, Butterbach K, Caan BJ, Carlson CS, Chan AT, Chang-Claude J, Chanock S, et al. Estimating the heritability of colorectal cancer. Hum Mol Genet. 2014;23(14):3898-905.

3. MacArthur J, Bowler E, Cerezo M, Gil L, Hall P, Hastings E, Junkins H, McMahon A, Milano A, Morales J, et al. The new NHGRI-EBI catalog of published genome-wide association studies (GWAS catalog). Nucleic Acids Res. 2017;45(D1):D896-901.

4. Manolio TA, Collins FS, Cox NJ, Goldstein DB, Hindorff LA, Hunter DJ, McCarthy MI, Ramos EM, Cardon LR, Chakravarti A, et al. Finding the missing heritability of complex diseases. Nature. 2009;461(7265):747-53.

5. Tan EK. Genome-wide association studies: promises and pitfalls. Ann Acad Med Singap. 2010;39(2):77-8.

6. Hutter CM, Chang-Claude J, Slattery ML, Pflugeisen BM, Lin Y, Duggan D, Nan H, Lemire M, Rangrej J, Figueiredo JC, et al. Characterization of geneenvironment interactions for colorectal cancer susceptibility loci. Cancer Res. 2012; $72(8): 2036-44$.

7. Kantor ED, Hutter CM, Minnier J, Berndt SI, Brenner H, Caan BJ, Campbell PT, Carlson CS, Casey G, Chan AT, et al. Gene-environment interaction involving recently identified colorectal cancer susceptibility loci. Cancer Epidemiol Biomark Prev. 2014:23(9):1824-33.

8. Kocarnik JD, Hutter CM, Slattery ML, Berndt SI, Hsu L, Duggan DJ, Muehling J, Caan BJ, Beresford SA, Rajkovic A, et al. Characterization of 9p24 risk locus and colorectal adenoma and cancer: gene-environment interaction and meta-analysis. Cancer Epidemiol Biomark Prev. 2010;19(12):3131-9.

9. Yang B, Thyagarajan B, Gross MD, Fedirko V, Goodman M, Bostick RM. No evidence that associations of incident, sporadic colorectal adenoma with its major modifiable risk factors differ by chromosome 8q24 region rs6983267 genotype. Mol Carcinog. 2014:53(Suppl 1):E193-200.

10. Alonso-Molero J, Gonzalez-Donquiles C, Palazuelos C, Fernandez-Villa T, Ramos E, Pollan M, Aragones N, Llorca J, Henar Alonso M, Tardon A, et al. The RS4939827 polymorphism in the SMAD7 GENE and its association with Mediterranean diet in colorectal carcinogenesis. BMC Med Genet. 2017; 18(1):122.

11. Song N, Shin A, Jung HS, Oh JH, Kim J. Effects of interactions between common genetic variants and smoking on colorectal cancer. BMC Cancer. 2017;17(1):869.

12. Song $\mathrm{N}$, Shin A, Oh JH, Kim J. Effects of interactions between common genetic variants and alcohol consumption on colorectal cancer risk. Oncotarget. 2018;9(5):6391-401.

13. Song N, Shin A, Park JW, Kim J, Oh JH. Common risk variants for colorectal cancer: an evaluation of associations with age at cancer onset. Sci Rep. 2017;7:40644.

14. Siegert S, Hampe J, Schafmayer C, von Schonfels W, Egberts JH, Forsti A, Chen B, Lascorz J, Hemminki K, Franke A, et al. Genome-wide investigation of gene-environment interactions in colorectal cancer. Hum Genet. 2013; 132(2):219-31.

15. Mukherjee B, Ahn J, Gruber SB, Chatterjee N. Testing gene-environment interaction in large-scale case-control association studies: possible choices and comparisons. Am J Epidemiol. 2012;175(3):177-90.

16. Albert PS, Ratnasinghe D, Tangrea J, Wacholder S. Limitations of the caseonly Design for Identifying Gene-Environment Interactions. Am J Epidemiol. 2001:154(8):687-93.

17. Colorectal Cancer Prevention (PDQ ${ }^{\circledR}$. Health professional version. PDQ cancer information summaries [Internet]. Bethesda: National Cancer Institute (US); 2002. 2018 Mar 1 edn; 2018.

18. American Cancer Society. Colorectal cancer facts \& figures 2017-2019. Atlanta: American Cancer Society; 2017.

19. Ahn Y, Kwon E, Shim JE, Park MK, Joo Y, Kimm K, Park C, Kim DH. Validation and reproducibility of food frequency questionnaire for Korean genome epidemiologic study. Eur J Clin Nutr. 2007;61(12):1435-41.
20. Kweon S, Kim Y, Jang MJ, Kim Y, Kim K, Choi S, Chun C, Khang YH, Oh K. Data resource profile: the Korea National Health and nutrition examination survey (KNHANES). Int J Epidemiol. 2014;43(1):69-77.

21. Lee J, Shin $\mathrm{A}, \mathrm{Oh} \mathrm{JH}$, Kim J. The relationship between nut intake and risk of colorectal cancer: a case control study. Nutr J. 2018;17(1):37.

22. Study C, Houlston RS, Webb E, Broderick P, Pittman AM, Di Bernardo MC, Lubbe S, Chandler I, Vijayakrishnan J, Sullivan K, et al. Meta-analysis of genome-wide association data identifies four new susceptibility loci for colorectal cancer. Nat Genet. 2008;40:1426.

23. Zhou L, Xie J, Gu EL, Huang Y, Qu Y, Xu AP, Zhu Y, Wang H. Common genetic variant on BMP4 contributes to colorectal adenoma and cancer: a meta-analysis based on 15 studies. Cytokine. 2015;72(2):154-9.

24. Ho JW, Choi SC, Lee YF, Hui TC, Cherny SS, Garcia-Barcelo MM, CarvajalCarmona L, Liu R, To SH, Yau TK, et al. Replication study of SNP associations for colorectal cancer in Hong Kong Chinese. Br J Cancer. 2011;104(2):369-75.

25. Yang $C Y$, Lu RH, Lin CH, Jen CH, Tung CY, Yang SH, Lin JK, Jiang JK, Lin CH. Single nucleotide polymorphisms associated with colorectal cancer susceptibility and loss of heterozygosity in a Taiwanese population. PLoS One. 2014:9(6):e100060.

26. Xiong F, Wu C, Bi X, Yu D, Huang L, Xu J, Zhang T, Zhai K, Chang J, Tan W, et al. Risk of genome-wide association study-identified genetic variants for colorectal cancer in a Chinese population. Cancer Epidemiol Biomark Prev. 2010;19(7):1855-61.

27. Lubbe SJ, Pittman AM, Olver B, Lloyd A, Vijayakrishnan J, Naranjo S, Dobbins S, Broderick P, Gomez-Skarmeta JL, Houlston RS. The 14q22.2 colorectal cancer variant rs4444235 shows cis-acting regulation of BMP4. Oncogene. 2012;31(33):3777-84

28. Gordon KJ, Blobe GC. Role of transforming growth factor- $\beta$ superfamily signaling pathways in human disease. Biochim Biophys Acta (BBA) - Mol Basis Dis. 2008;1782(4):197-228.

29. Potter JD. Colorectal Cancer: molecules and populations. J Natl Cancer Inst. 1999;91(11):916-32.

30. Jia W-H, Zhang B, Matsuo K, Shin A, Xiang Y-B, Jee SH, Kim D-H, Ren Z, Cai $\mathrm{Q}$, Long J, et al. Genome-wide association analyses in east Asians identify new susceptibility loci for colorectal cancer. Nat Genet. 2012;45:191.

31. William Querbes KF, Bettencourt B, Liebow A, Erbe DV. Compositions and methods for inhibition of HAO1 (Hydroxyacid Oxidase 1 (Glycolate Oxidase)) gene expression. Cambridge: Alnylam Pharmaceuticals, Inc.; 2017.

32. Hinkle G. Polynucleotide agents targeting hydroxyacid oxidase (glycolate oxidase, hao1) and methods of use thereof. Cambridge: Alnylam Pharmaceuticals, Inc:; 2017.

\section{Publisher's Note}

Springer Nature remains neutral with regard to jurisdictional claims in published maps and institutional affiliations.

\section{Ready to submit your research? Choose BMC and benefit from:}

- fast, convenient online submission

- thorough peer review by experienced researchers in your field

- rapid publication on acceptance

- support for research data, including large and complex data types

- gold Open Access which fosters wider collaboration and increased citations

- maximum visibility for your research: over $100 \mathrm{M}$ website views per year

At $\mathrm{BMC}$, research is always in progress.

Learn more biomedcentral.com/submissions 